\title{
Políticas públicas nacionais para apoiar pessoas com deficiência e suas famílias: Uma revisão integrativa
}

\author{
National public policies to support disabled people and their family: An integrative review \\ Políticas públicas nacionales para apoyar a las personas con discapacidad y sus familias: Una \\ revisión integrativa
}

Recebido: 13/04/2021 | Revisado: 21/04/2021 | Aceito: 24/04/2021 | Publicado: 09/05/2021

\author{
Ana Naysa Albuquerque Teixeira \\ ORCID: https://orcid.org/0000-0003-4695-2384 \\ Universidade Estadual Vale do Acaraú, Brasil \\ E-mail: naysateixeira@gmail.com \\ Cibelly Aliny Siqueira Lima Freitas \\ ORCID: https://orcid.org/0000-0002-0585-5345 \\ Universidade Estadual Vale do Acaraú, Brasil \\ E-mail: cibellyaliny@gmail.com \\ Isabelle Frota Ribeiro Queiroz \\ ORCID: https://orcid.org/0000-0002-9259-8833 \\ Universidade Estadual Vale do Acaraú, Brasil \\ E-mail: isabellefrota2010@hotmail.com \\ Francisco Breno de Sousa Lima \\ ORCID: https://orcid.org/0000-0002-0682-3492 \\ Universidade Estadual Vale do Acaraú, Brasil \\ E-mail:breno_soulima@hotmail.com \\ Luís Henrique Azevedo Moreira \\ ORCID: https://orcid.org/0000-0003-3803-0259 \\ Universidade Estadual Vale do Acaraú, Brasil \\ E-mail: luishenriqueazevedosh@gmail.com \\ Verônica de Azevedo Mazza \\ ORCID: https://orcid.org/0000-0002-1264-7149 \\ Universidade Federal do Paraná, Brasil \\ E-mail: vera62mazza@gmail.com \\ Benedita Shirley Carlos Rosa \\ ORCID: https://orcid.org/0000-0002-9125-3614 \\ Universidade Estadual Vale do Acaraú, Brasil \\ E-mail: shirleyrosa08@gmail.com \\ Ana Caroline Lira Bezerra \\ ORCID: https://orcid.org/0000-0002-2432-4814 \\ Universidade Federal do Ceará, Brasil \\ E-mail: ana.caroline_bezerra@hotmail.com
}

\begin{abstract}
Resumo
Trata-se de uma revisão integrativa da literatura que tem por objetivo analisar as produções científicas sobre políticas públicas nacionais brasileiras voltadas às pessoas com deficiência e suas famílias. Foi realizado no mês de Outubro/2020, nas bases de dados da Biblioteca Virtual de Saúde (BVS), utilizando os descritores "políticas públicas", "deficiência" e "família". A partir dos critérios de elegibilidade, foram selecionados 16 documentos. Diante da leitura dos artigos, observou-se que políticas públicas focadas nas pessoas com deficiência ainda se encontram incipientes. Também constatou- se a ausência de políticas voltadas para capacitação, informação e atenção aos cuidadores. Os resultados evidenciaram que as produções científicas sobre as políticas públicas nacionais que apoiam a pessoa com deficiência e sua família se apresentam de forma insatisfatória no meio das produções científicas.
\end{abstract}

Palavras-chave: Políticas públicas; Pessoas com deficiência; Família.

\begin{abstract}
An integrative review aimed to analyze scientific productions about national public policies regarding disabled people and their family. Data collection was performed in October 2020, in all available databases at Virtual Health Library (BVS), using "public policy", "disability", and "family" as descriptors. From the eligibility requirements, 16 documents were selected. When reading the articles, public policies focused on people with disabilities are still reduced. We also note the absence of policies aimed at training, information and care for caregivers. The results showed that scientific productions about public policies that support a person with disabilities and his family are unsatisfactory in the middle of scientific productions.
\end{abstract}

keywords: Public policy; Disabled persons; Family. 


\section{Resumen}

Esta es una revisión de literatura integradora que tiene como objetivo analizar la producción científica sobre políticas públicas nacionales dirigidas a personas con discapacidad y sus familias. Se realizó en octubre de 2020, en las bases de datos de la Biblioteca Virtual en Salud (BVS), utilizando los descriptores "políticas públicas", "discapacidad" y "familia". De los criterios de elegibilidad, se seleccionaron 16 documentos. Al leer los artículos, se observó que las políticas públicas centradas en las personas con discapacidad todavía se reducen. También hubo una falta de políticas destinadas a la capacitación, la información y la atención de los cuidadores. Los resultados mostraron que las producciones científicas sobre políticas públicas nacionales que apoyan a las personas con discapacidad y sus familias son insatisfactorias en medio de las producciones científicas.

Palabras clave: Política pública; Personas con discapacidad; Familia.

\section{Introdução}

A deficiência pode ser definida como a perda ou anormalidade de uma estrutura ou função anatômica, psicológica ou fisiológica, podendo gerar incapacidade ou dificuldade para a realização de atividades comuns (França et al., 2010). Se apresenta, também, como um aspecto da condição humana, pois pode acometer as pessoas em algum período da vida, de forma temporária ou permanente. Inclusive através das consequências do próprio envelhecimento (OMS, 2011).

No Brasil, segundo o Instituto Brasileiro de Geografia e Estatística (2010), 45.606.048 brasileiros, ou seja, 23,9\% da população total, possui algum tipo de deficiência: visual, auditiva, motora e mental ou intelectual. Além disso, a prevalência da deficiência variou conforme a natureza delas. A visual apresentou a maior ocorrência, afetando 18,6\% da população brasileira. Em segundo lugar está a motora, ocorrendo em 7\% da população, seguida pela auditiva, em 5,10\%, e da mental ou intelectual, em $1,40 \%$.

Os dados do censo mostraram que a deficiência atinge as pessoas em qualquer idade, quer seja de forma congênita ou adquirida no decorrer da vida. O contingente populacional que teve pelo menos uma das deficiências investigadas pelo Censo de 2010 revela que sua prevalência é bastante alta na população brasileira e se distribui por todos os grupos etários. No entanto, os dados demonstram acentuado aumento nas faixas etárias de 5 a 9 anos e de 40 a 44 anos (IBGE, 2010).

Dessas pessoas, 38.473 .702 se encontravam em áreas urbanas e 7.132.347, em áreas rurais. A Região Nordeste concentra os municípios com os maiores percentuais da população com pelo menos uma das deficiências investigadas. Segundo dados do IBGE (2010), o Ceará soma pelo menos 2.340.150 pessoas com deficiência e ocupa o terceiro lugar entre os estados brasileiros, sendo que o percentual da população residente no Estado com alguma deficiência (27,69\%) supera o índice nordestino $(26,63 \%)$ e nacional $(23,92 \%)$.

Nessa perspectiva, a deficiência pode ser tratada com um fenômeno global, que está constantemente associado à pobreza, com impactos políticos, econômicos, culturais e sociais, além de implicações para a sociedade como um todo. Percebese, também, que a ausência da acessibilidade para as pessoas com deficiência ainda persiste, principalmente, em locais públicos, os quais não dispõem de espaços adequados para receber pessoas com necessidades específicas (Martins et al., 2010), A dificuldade do acesso pode causar interferência, que dificultam no modo de prevenção a saúde, o que geraria mais custos ou problemas de maiores gravidades a saúde (Martins et al., 2018).

O Brasil tem avançado na implementação de leis e planos para apoio ao exercício da capacidade legal das pessoas com deficiência. Dessa forma, a legislação brasileira é desenvolvida a partir da definição do diagnóstico médico, enquanto o modelo social, a define como barreiras físicas, organizacionais e atitudes presentes na sociedade. A Convenção sobre os Direitos da Pessoa com Deficiência levantou o debate da eliminação de barreiras, possibilitando essa população viver independente e participar ativamente na sociedade (Bernardes \& Araújo, 2012).

Historicamente, a construção das políticas públicas no Brasil nos mostra que as conquistas aconteceram com a participação dos diferentes segmentos sociais, que a partir de uma organização coletiva têm buscado garantir seus direitos. Desde os anos 2000, quando diversos programas e políticas começaram um processo de internalização dos direitos humanos na agenda 
do poder público, envolvendo as pessoas com deficiência, a partir de normas legais, como as leis da acessibilidade (Leis $n^{\circ}$ 10.048 e no 10.098, de 2000) e, posteriormente, da Convenção da Organização das Nações Unidas (ONU) sobre os Direitos da Pessoa com Deficiência, em 2006, trouxeram temas novos para a agenda de direitos.

Em 2011, o Plano Nacional dos Direitos da Pessoa com Deficiência - o Viver sem Limite -, o primeiro a ser dimensionado na perspectiva intersetorial no País, apresentou um novo desafio: um tema que por décadas esteve apenas no cenário da assistência e da educação agora precisava ter novas traduções no âmbito dos operadores de políticas públicas.

Nesse ínterim, insere-se a família a qual é responsável pelo desenvolvimento humano de todo indivíduo, por ser o primeiro contato em que estão inseridos, caracterizando-se como o apoio fundamental do ser humano. Segundo Luna e Naiff (2015), a família exerce diversos papéis, dentre eles a socialização, a proteção e o cuidado. Assim, entende-se que a família se configura como o principal grupo social influenciado pela existência de pessoas com deficiência entre seus membros. E, é a partir dela que a deficiência toma sentidos e significados específicos.

Com isso, torna- se importante que a família possua conhecimento acerca dos direitos legais, para que haja a inclusão da pessoa com deficiência. Portanto, o acesso a informações fidedignas sobre políticas públicas desempenham papel fundamental, na qual elas deveriam garantir o acesso ao acompanhamento ininterrupto dessas pessoas e seus familiares (Holanda, Collet \& Costa, 2008).

Diante dessa realidade, o presente artigo tem como objetivo analisar as produções científicas sobre políticas públicas nacionais brasileiras voltadas às pessoas com deficiência e suas famílias.

\section{Metodologia}

Trata-se de uma revisão integrativa, onde buscou-se evidências científicas que abordassem e discutissem acerca de políticas públicas voltadas à pessoa com deficiência e sua família. Nesse tipo de estudo, a análise de pesquisas relevantes é realizada desta maneira fornecer subsídios para a tomada de decisões e a melhoria das práticas clínicas, possibilitando a síntese do conhecimento de um determinado assunto, além de evidenciar a necessidade da realização de novos estudos (Mendes, Silveira \& Galvão, 2008).

Este estudo consiste na sistematização de publicações teóricas seguindo as etapas estabelecidas por Ganong (1987): seleção da questão temática ou questão-problema, estabelecimento dos critérios para a seleção da amostra, representação das características da pesquisa original, análise dos dados, interpretação dos resultados e apresentação da revisão.

Para isso, este estudo norteia-se pela seguinte questão de pesquisa: Quais políticas públicas nacionais têm sido implementadas para apoiar a pessoa com deficiência e sua família?

O levantamento bibliográfico foi realizado durante o mês de outubro de 2020. Os descritores foram delimitados a partir da busca nos Descritores em Ciências da Saúde (DECS), da qual foram definidos "Políticas Públicas", "Deficiência" e "Família" para fundamentar a busca na base de dados. Estes foram utilizados associados ao operador boleano and com o uso de aspas e sem método de truncagem. A busca dos documentos foi realizada em todas as bases de dados disponíveis na Biblioteca Virtual de Saúde (BVS).

Nesse sentido, com os resultados da busca na base de dados, fez-se necessário a delimitação de critérios de elegibilidade para selecionar os documentos. Assim, adotou- se como critérios de inclusão: produções bibliográficas escritas em língua portuguesa, com acesso on line ao texto completo, e publicados em revistas científicas indexadas na BVS. Foram excluídos: artigos que estavam repetidos nas bases de dados, textos que não são artigos e material bibliográfico com enfoque diferente da temática em estudo. É importante destacar que não houve delimitação do corte temporal para a escolha dos documentos. Dessa forma, a amostra foi composta de todas as publicações que se enquadraram nos critérios até Outubro de 2020. 
Após realização da busca, foram identificados 92 documentos resultantes do cruzamento dos descritores. Por meio das estratégias de busca, elegibilidade e após a leitura dos títulos, foram incluídos 16 artigos para compor o corpus deste estudo, os quais estavam disponíveis na Base de Dados de Enfermagem (BDEnf), Literatura Latino-Americana e do Caribe em Ciências da Saúde (Lilacs) e Index Psicologia - Periódicos técnico-científicos. O processo de seleção dos estudos está apresentado na Figura 1, conforme recomendação PRISMA statemente (Preferred Reporting Items for Systematic Reviews and Meta-Analysis) (Moher, Liberati \& Tetzlaff, 2009).

Figura 1. Fluxograma de identificação e seleção dos estudos.

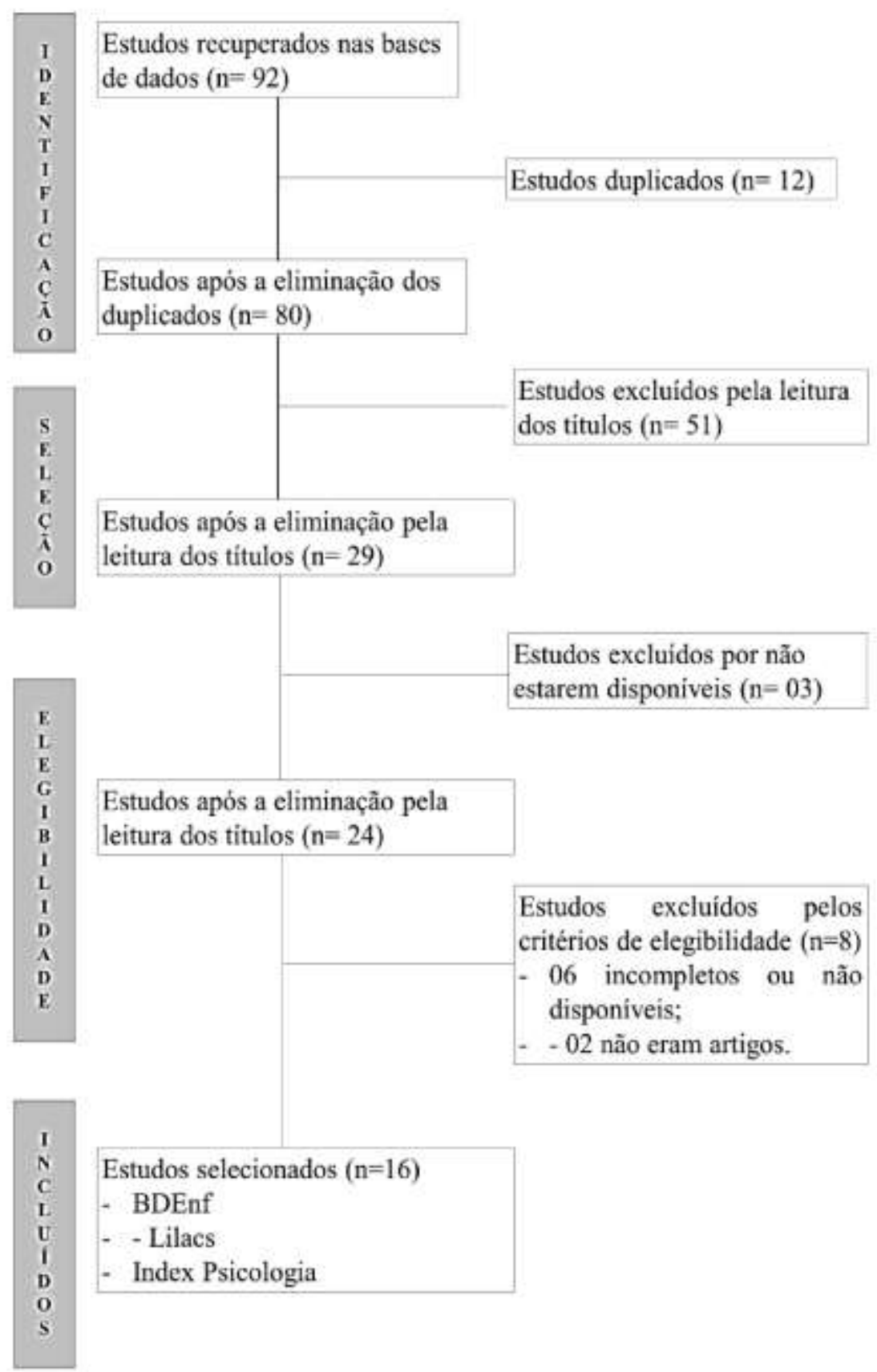

Fonte: Autores. 
Os artigos resultantes foram lidos na íntegra e, para coleta de informações foi adaptado instrumento apresentado por Ursi (2005), o qual propõe informações gerais dos documentos e específicas direcionadas a propostas metodológicas, principais achados e contribuições para o conhecimento científico. Com isso, o instrumento contemplou as seguintes variáveis: periódico, título do artigo, autores, ano de publicação, cidade/estado e tipo de estudo.

Para a análise das informações, optou-se por utilizar a análise temática, onde foram respeitadas as etapas de pré-análise, exploração do material de pesquisa, tratamento dos resultados obtidos e interpretação na perspectiva de delinear os processos de construção do saber expostos nos documentos analisados (Minayo, 2006).

\section{Resultados e Discussões}

A análise dos documentos selecionados permitiu a condução de achados pertinentes para a discussão sobre políticas públicas nacionais que têm sido implementadas para apoiar a pessoa com deficiência e sua família. Foram utilizadas informações relacionadas aos aspectos estruturais, delineamento teórico-metodológico e os resultados dos artigos.

Quadro 1. Aspectos gerais dos artigos analisados, 2020.

\begin{tabular}{|c|c|c|c|}
\hline Título de Artigo & Autores, Ano & Tipo de Estudo & Periódico \\
\hline $\begin{array}{l}\text { Escolarização da pessoa com deficiência } \\
\text { intelectual: Terminalidade específica e } \\
\text { expectativas Familiares }\end{array}$ & $\begin{array}{l}\text { Lima \& Mendes, } \\
2011\end{array}$ & $\begin{array}{l}\text { Estudo de campo de } \\
\text { caráter analítico }\end{array}$ & $\begin{array}{l}\text { Revista Brasileira } \\
\text { Educação Especial }\end{array}$ \\
\hline $\begin{array}{l}\text { Caracterização de famílias de mãe com } \\
\text { deficiência intelectual e os efeitos no } \\
\text { desenvolvimento dos filhos. }\end{array}$ & $\begin{array}{l}\text { Postalli, Munuera \& } \\
\text { Aielo, } 2011\end{array}$ & Relato de pesquisa & $\begin{array}{l}\text { Revista Brasileira } \\
\text { Educação Especial }\end{array}$ \\
\hline $\begin{array}{l}\text { Famílias de crianças e adolescentes com } \\
\text { autismo: Cotidiano e realidade de cuidados } \\
\text { em diferentes etapas do desenvolvimento }\end{array}$ & $\begin{array}{l}\text { Minatel } \\
\text { Matsukura, } \\
2012\end{array}$ & $\begin{array}{l}\text { Estudo quantitativo, } \\
\text { qualitativo descritivo }\end{array}$ & 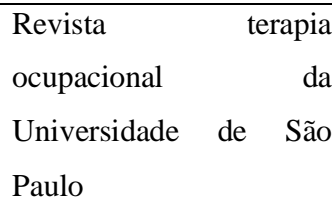 \\
\hline $\begin{array}{l}\text { Indicadores de saúde auditiva em Minas } \\
\text { Gerais - um estudo por macrorregião. }\end{array}$ & Maciel et al, 2013 & $\begin{array}{l}\text { Estudo de abordagem } \\
\text { quantitativa, analítico } \\
\text { transversal }\end{array}$ & $\begin{array}{l}\text { Audiology- } \\
\text { Communication } \\
\text { Research (ACR) }\end{array}$ \\
\hline $\begin{array}{l}\text { Vulnerabilidade das crianças com } \\
\text { necessidades especiais de saúde: implicações } \\
\text { para a enfermagem. }\end{array}$ & $\begin{array}{l}\text { Silveira \& Neves, } \\
2012\end{array}$ & $\begin{array}{l}\text { Pesquisa qualitativa } \\
\text { descritiva } \\
\text { exploratória }\end{array}$ & $\begin{array}{l}\text { Revista Gaúcha de } \\
\text { Enfermagem }\end{array}$ \\
\hline $\begin{array}{l}\text { Identificando necessidades de crianças com } \\
\text { deficiência auditiva: uma contribuição para } \\
\text { profissionais de saúde e educação. }\end{array}$ & $\begin{array}{l}\text { Scarpitta, Vieira \& } \\
\text { Dupas, } 2011\end{array}$ & $\begin{array}{l}\text { Interacionismo } \\
\text { Simbólico e Narrativa }\end{array}$ & Escola Anna Nery \\
\hline $\begin{array}{l}\text { Estratégias de enfrentamento enfrentado por } \\
\text { pais de crianças com deficiência intelectual }\end{array}$ & $\begin{array}{l}\text { Santos, Pereira \& } \\
\text { Martins, } 2016\end{array}$ & Revisão integrativa & $\begin{array}{l}\text { Ciência \& Saúde } \\
\text { Coletiva }\end{array}$ \\
\hline $\begin{array}{l}\text { A criança com síndrome de Down: na } \\
\text { perspectiva do Desenvolvimento Humano, } \\
\text { com destaque aos fatores de risco e de } \\
\text { proteção. }\end{array}$ & Pontes et al, 2013 & $\begin{array}{l}\text { Teoria Bioecológica } \\
\text { do Desenvolvimento } \\
\text { Humano }\end{array}$ & $\begin{array}{l}\text { Boletim Academia } \\
\text { Paulista de Psicologia }\end{array}$ \\
\hline
\end{tabular}




\begin{tabular}{|c|c|c|c|}
\hline $\begin{array}{l}\text { Representações sociais da deficiência nas } \\
\text { famílias: um estudo comparativo. }\end{array}$ & Luna \& Naiff, 2015 & $\begin{array}{l}\text { Pesquisa Comparativa } \\
\text { e Abordagem } \\
\text { Qualitativa }\end{array}$ & Psicologia e Saber social \\
\hline $\begin{array}{l}\text { Crianças com Síndrome de Down: o } \\
\text { significado do cuidar na percepção de mães. }\end{array}$ & Holanda et al, 2016 & $\begin{array}{l}\text { Pesquisa exploratória } \\
\text { com abordagem } \\
\text { qualitativa }\end{array}$ & $\begin{array}{l}\text { Online Brazilian Journal } \\
\text { of Nursing }\end{array}$ \\
\hline $\begin{array}{l}\text { Perfil do Cuidador de Pessoas com } \\
\text { Deficiência. }\end{array}$ & Câmara et al, 2016 & $\begin{array}{l}\text { Transversal } \\
\text { abordagem } \\
\text { quantitativa }\end{array}$ & $\begin{array}{l}\text { Revista Brasileira de } \\
\text { ciências da saúde }\end{array}$ \\
\hline $\begin{array}{l}\text { Correlação entre o Relacionamento Conjugal, } \\
\text { Rotina Familiar, Suporte Social, } \\
\text { Necessidades e Qualidade de Vida de Pais e } \\
\text { Mães de Crianças com Deficiência. }\end{array}$ & $\begin{array}{l}\text { Azevedo, Cia e } \\
\text { Spinazola (2019) }\end{array}$ & $\begin{array}{l}\text { Transversal } \\
\text { abordagem } \\
\text { quantitativa }\end{array}$ & $\begin{array}{l}\text { Revista Brasileira } \\
\text { Educação Especial }\end{array}$ \\
\hline $\begin{array}{l}\text { Fatores que interferem no processo de } \\
\text { inclusão de bebês com deficiência física no } \\
\text { berçário. }\end{array}$ & $\begin{array}{l}\text { Bossi, Junges \& } \\
\text { Piccinini, } 2018 .\end{array}$ & $\begin{array}{l}\text { Estudo descritivo e } \\
\text { transversal }\end{array}$ & $\begin{array}{l}\text { Psicologia Escolar } \mathrm{e} \\
\text { Educacional }\end{array}$ \\
\hline $\begin{array}{l}\text { Custos adicionais da pessoa com deficiência } \\
\text { física - São Paulo e Brasil. }\end{array}$ & $\begin{array}{l}\text { Kanikadan, P.Y.S., } \\
\text { et al. (2019) }\end{array}$ & $\begin{array}{l}\text { Pesquisa qualitativa de } \\
\text { Padrão Orçamentário }\end{array}$ & $\begin{array}{l}\text { Jornal Brasileiro de } \\
\text { Economia da Saúde }\end{array}$ \\
\hline $\begin{array}{l}\text { Mobiliários e instalações sanitárias em } \\
\text { unidades de saúde da família: acessibilidade } \\
\text { física para pessoas com deficiência. }\end{array}$ & $\begin{array}{l}\text { Martins, K., } \\
\text { Medeiros, T., Costa, } \\
\text { T., Macêdo Costa, } \\
\text { K., \& França, I. } \\
(2018)\end{array}$ & $\begin{array}{l}\text { Pesquisa descritiva } \\
\text { exploratória }\end{array}$ & $\begin{array}{l}\text { Revista de Pesquisa: } \\
\text { Cuidado é Fundamental } \\
\text { Online }\end{array}$ \\
\hline $\begin{array}{l}\text { Direitos sociais das crianças com condições } \\
\text { crônicas: análise crítica das políticas públicas } \\
\text { brasileiras }\end{array}$ & $\begin{array}{l}\text { Tavares, } \\
\text { Duarte., E. E. } \\
\text { Sena, R. \& } \quad \text { R de. } \\
\text { (2017). }\end{array}$ & $\begin{array}{l}\text { Pesquisa documental } \\
\text { de legislações }\end{array}$ & Esc. Anna Nery \\
\hline
\end{tabular}

Fonte: Autores.

Os estudos foram realizados em estados da região nordeste, sul e sudeste, entre os anos 2011 e 2019. Sendo, estes, os anos que obtiveram mais publicações. No que tange aos meios de divulgação desses periódicos, houve a predominância na área da saúde.

Quanto ao teor metodológico dos artigos, o tipo de estudo mais predominante entre eles foi o exploratório e o qualitativo. Além disso, os periódicos que mais contribuíram para a pesquisa foram a Revista Brasileira de Educação Especial.

Diante de uma leitura minuciosa dos artigos selecionados, emergiram as seguintes categorias para análise e discussão das informações: (1) Políticas de atenção à saúde auditiva; (2) Políticas de integração à pessoa com deficiência e (3) Políticas direcionadas à família de pessoas com deficiência.

\section{Políticas de atenção à saúde auditiva}

A Política Nacional de Atenção à Saúde Auditiva, instituída pela Portaria do Ministério da Saúde nº 2.073/04 (Brasil, 2004), iniciou discussões acerca da atenção integral e integrada aos indivíduos com deficiência auditiva que são usuários do Sistema Único de Saúde (SUS). Um dos principais objetivos dessa política é garantir que as doutrinas do SUS (universalidade, 
equidade e integralidade), cheguem de forma ampla para esse público. Essa política busca utilizar estratégias para a promoção da qualidade de vida, educação, proteção e recuperação da saúde e controle de danos, de modo a proteger e desenvolver autonomia e equidade dos indivíduos (Maciel, 2013).

Mesmo com todos os métodos disponíveis para detectar o problema, ainda existe muita dificuldade em diagnosticar precocemente a surdez infantil. Com isso, a Lei das Diretrizes e Bases da Educação (LDB, n 9.394/96) (Brasil,1996), assegura que todos os serviços de educação tenham pessoas capacitadas para atender qualquer forma de deficiência do aluno (Scarpitta, Vieira \& Dupas, 2011).

O direito à Saúde engloba não somente o âmbito da preservação da integridade física, mas também, a sanitária, ambiental, mental e social. Além disso, este direito se refere aos aspectos estático e individual, bem como, relaciona-se ao desenvolvimento da pessoa como um ser holístico cultural, e a sua relação com a sociedade. Para tanto, o SUS institucionalizado pela Constituição Federal de 88, menciona a saúde como direito de todos e dever do Estado. Além disso, conforme o Art. $7^{\circ}$ da Lei 8.080/90 as ações e serviços de saúde devem ser desenvolvidos, obedecendo aos princípios: "I - universalidade de acesso à saúde; III - preservação da autonomia das pessoas na defesa de sua integridade física e moral; IV - igualdade da assistência" (Filha, Silva \& Lando, 2015).

Diante desse contexto, é preciso atentar como esses direitos estão resguardados os que pertencem a grupos minorizados, como as pessoas com deficiência, especialmente, com surdez, observando se de fato, as políticas públicas têm sido implementadas, ampliadas e aperfeiçoadas no sentido de promover a dignidade humana e cidadania.

\section{Políticas de integração à pessoa com deficiência}

O olhar para a pessoa com deficiência tem se modificado ao longo dos anos. A Constituição Federal de 1988 (Brasil, 1988) foi a primeira a relatar sobre o direito dessas pessoas. A partir disso, foram promulgadas diversas outras, como: o decreto no 3.298/99 (Brasil,1999) que regula a Lei 7.853/89 (Brasil,1989) a qual instituiu a Política Nacional para Integração da Pessoa Portadora de Deficiência, considerada a primeira política pública voltada especificamente, para as pessoas com deficiência. Essa norma dispõe sobre a discriminação e trata do apoio e integração social dessas pessoas.

A legislação tem procurado incluir as pessoas com deficiências e dar seguimento na vida acadêmica e profissional através da Lei de Diretrizes e Bases da Educação Nacional (LDB) nº 9394/96, que sinaliza o acesso do aluno com necessidades educacionais especiais à escola comum. Também preconiza que os sistemas de ensino deverão assegurar um desfecho específico para aqueles que não poderão atingir o nível exigido para a conclusão do ensino fundamental em virtude de suas deficiências, bem como aceleração para concluir em menor tempo o programa escolar para os superdotados (Lima \& Mendes, 2011).

A análise dos artigos aponta que famílias de pessoas com deficiência intelectual, relatam expectativas positivas em relação ao desenvolvimento deles de modo geral, quando estão inseridos no ambiente escolar, além de ser um meio de socialização e alfabetização.

Apesar das melhorias relacionadas à escolarização dos alunos com deficiência intelectual, as terminalidades específicas devem evoluir, para que, dessa forma, as famílias possam superar suas expectativas (Lima \& Mendes, 2011). Considerando que as famílias não buscam o ambiente escolar apenas pela certificação, mas, sim, pela possibilidade de socialização com o mundo e inclusão dessas pessoas na sociedade como um ato político social, além do acesso aos direitos que nos remetem à promoção da dignidade humana. Contudo, observa-se que as políticas públicas já implantadas são limitadas, necessitando da implementação de novos métodos com o propósito de garantir o ensino de acordo com as condições específicas existentes.

Outros fatores importantes para a inclusão escolar, envolvem a qualificação de profissionais para lecionar, buscando ter um olhar integral, propor atividades que reconheçam as potencialidades e as limitações das crianças. As escolas devem ter 
adaptações em sua estrutura física, materiais e didáticas destinadas a atender as necessidades. A intersetorialidade entre os serviços de educação e saúde pode possibilitar a garantia de direitos à pessoa com deficiência (Bossi, Junges \& Piccinini, 2018). A educação continuada da equipe multiprofissional de saúde é um passo importante para assistência inclusiva que abrange as crianças e seus familiares, causando repercussões positivas para a construção de vínculo que facilitarão os cuidados, proporcionando comunicação efetiva, confiança, acolhimento humanizado, e assistência de qualidade de acordo com a singularidade. (Silva et al., 2019)

No que concerne ao direito reprodutivo a qualquer cidadão, as pessoas com deficiências também possuem o direito de gerar filhos e constituir famílias. No entanto, essa questão é um pouco complexa em virtude da estigmatização dessas pessoas, pois alguns pesquisadores possuem a percepção de que pessoas com deficiência não tenham condições de prover cuidados essenciais aos seus filhos, em detrimentos de outros pesquisadores acreditarem que o baixo quociente não é um a fator preditivo da inadequação parental, desde de que os pais com dificuldade intelectual tenham oportunidade de aprender comportamentos adequados e necessários com criança (Postalli, Munuera \& Aiello, 2011).

Nos artigos estudados foram destacadas as Políticas de proteção aos direitos da pessoa com Transtorno do Espectro Autista (TEA), as quais abordam o transtorno como pertencente ao campo das deficiências, propondo o tratamento pela via da reabilitação. O reconhecimento do autismo como uma deficiência gerou um novo debate em torno das formas como esta população específica deve ser contemplada no rol de ações e serviços disponíveis no SUS para além da assistência que vinha sendo provida. Nesse contexto, em 2013 foram lançados pelo Ministério da Saúde (MS) dois documentos que tinham por objetivo fornecer orientações para o tratamento e acompanhamento das pessoas com TEA no SUS.

A Política Nacional de Proteção aos direitos da Pessoas com Transtorno do Espectro Autista, instituída através da Lei 12.764 (Brasil, 2012) foi um marco legal ao considerar a pessoa com autismo como pessoa com deficiência. A partir disso, reforçou-se, a garantia de direitos à educação, assistência social, tratamentos adequados e especializados.

Um deles foi o documento intitulado "Diretrizes de Atenção à Reabilitação da Pessoa da Pessoa com Transtorno do Espectro Autista (TEA)" (BRASIL, 2014), cuja abordagem remete o autismo ao campo das deficiências, direcionando a terapêutica pela via da reabilitação. O outro, a "Linha de Cuidado para a Atenção às Pessoas com Transtornos do Espectro do Autismo e suas Famílias na Rede de Atenção Psicossocial do Sistema Único de Saúde" (BRASIL, 2015), concebe o TEA como um transtorno mental, atrelando as ações de cuidado à rede de atenção psicossocial, com destaque para os Centro de Apoio Psicossocial infantil (CAPSi).

Essas iniciativas se configuram como necessárias diante do prejuízo funcional nas áreas da comunicação, interação social e do comportamento, geradas pelo autismo. Tais comprometimentos geram impactos tanto na vida da pessoa com autismo, quanto para seu grupo familiar. Podendo, também, promover sofrimento aos pais ou não, em virtude dos efeitos estressantes da severidade das características da criança, a disponibilidade de recursos comunitários e sociais, dentre outros (Minotel \& Matsukura, 2014).

\section{Políticas direcionadas à família de pessoas com deficiência}

Uma peça fundamental para a inclusão da pessoa com deficiência na sociedade é o cuidador, sendo aquele que exerce o ato de cuidar. Ele é responsável por desenvolver atividades que envolvam e inclua a pessoa com deficiência no meio social, assim como oferecer ações de proteção, prevenção e recuperação da saúde, dar carinho, amor, compreensão, escuta e apoio emocional. Uma pesquisa realizada por Câmara (2016) em João Pessoa-PB mostra que, 91,1\% dos cuidadores pesquisados são familiares, e destes 96,3\% não foram capacitados para cuidar. Apenas 44,3\% foram beneficiados com alguma informação, e, desses, 26,6\% foram orientados pela Atenção Primária à Saúde. 
Os resultados dos artigos evidenciaram a ausência de políticas públicas voltadas para a capacitação, informação e atenção aos cuidadores. Devido cuidador não possuir destaque na saúde pública, faz-se necessário que haja uma ampliação e fortificação destas, para que ele também seja contemplado e, dessa forma, o cuidado seja mais eficiente (Câmara et al., 2016).

Para Azevedo, Cia e Spinazola (2019) é importante proporcionar serviços, projetos e programas que abranjam as famílias e considere suas solicitações. Embora exista, há precisão de mais engajamento dos pais em programas de intervenções tendo as mães como maiores provedoras dos cuidados dos filhos.

A deficiência repercute no lado financeiro da família inclusive para o empobrecimento, pois devido às necessidades de gastos para os cuidados a renda fica direcionada a pessoa com deficiência. Causando redução no padrão de vida e bem-estar dos familiares. Havendo necessidade por meio de políticas públicas que os serviços estejam qualificados com materiais, equipamentos, inclusive com suportes financeiros para prestar tais cuidados (Kanikadan et al., 2019).

Vale destacar um estudo realizado por Luna' e Naiff (2015), onde o grupo de pessoas que possui um convívio longitudinal com a pessoa com deficiência, reconhece que, das categorias pesquisadas (políticas públicas, infraestrutura/acessibilidade, relações de convivência, informação e outros), a política pública é a que mais facilita a vida destes, pois estão mais voltadas às tarefas de rotina e que não se espera somente empatia, amor ou respeito, mas também, condições que favoreçam a dignidade e a cidadania.

\section{Considerações Finais}

As produções permitiram identificar evidências disponíveis na literatura relacionada às políticas públicas nacionais voltadas para apoiar pessoas com deficiência e sua família. O resultado sugere que este grupo de pessoas possuem algumas vulnerabilidades que são minimizadas com o apoio das políticas públicas existentes. Embora haja avanços, ainda existem lacunas a serem preenchidas e que impactam diretamente na vida dessas pessoas e de seus familiares, tornando-se, dessa forma, necessário a implantação de novas políticas com outras nuances para melhoria do quadro situacional vivenciado.

Considera-se, também, que o material apresentado neste artigo seja um ponto de partida para a reflexão e discussão sobre a implementação de políticas nacionais voltadas às pessoas com deficiências, bem como sua família, visto que esta se constitui como um operador de cuidados e responsável por processos fundamentais na efetivação do cuidado e garantia dos direitos. No que concerne às limitações deste estudo, relaciona-se a necessidade de ampliar possibilidades de análise que auxiliem o avanço dessas discussões com fins de qualificar a atenção a essa população específica e garantir a dignidade da pessoa com deficiência.

Sugere-se a realização de novos estudos sobre as políticas públicas voltadas as pessoas com deficiência e seus familiares, ampliando a busca para estudos internacionais com vistas a discutir políticas capazes de garantir a efetivação de direitos desse público, a partir do conhecimento de suas demandas e necessidades no sentido de construir uma sociedade mais inclusiva.

\section{Referências}

Azevedo, T. L , Cia, F., \& Spinazola,C. de C. (2019). Correlação entre o Relacionamento Conjugal, Rotina Familiar, Suporte Social, Necessidades e Qualidade de Vida de Pais e Mães de Crianças com Deficiência.. Revista Brasileira de Educação Especial,25(2), 205-218. https://doi.org/10.1590/s141365382519000200002

Bernardes, L. C. G., \& Araújo, T. C. C. F. (2012). Deficiência, políticas públicas e bioética: percepção de gestores públicos e conselheiros de direitos. Ciência \& Saúde Coletiva, 17 (9), 2435-2445.

Bossi, T. J., Jungues, A. P. P., \& Piccinini, C. A. (2018). Fatores que interferem no processo de inclusão de bebês com deficiência física no berçário. Psicologia Escolar e Educacional, 22(2), 377-384. https://doi.org/10.1590/2175-35392018011348

Brasil. (1988). Constituição, 1988. Constituição da República Federativa do Brasil. Senado Federal. p.292. 
Brasil. (1999). Regulamenta a Lei $n^{\circ} 7.853$ de 24 de outubro de 1989. Dispõe sobre a Política Nacional para a Integração da Pessoa Portadora de Deficiência, consolida as normas de proteção, e dá outras providências. Diário Oficial União. 1999. http://www.planalto.gov.br/ccivil_03/decreto/d3298.html. Acessado em $23 / 05 / 2020$.

Brasil. Presidência da República, Subchefia para Assuntos Jurídicos. (2000). Lei $n^{\circ}$ 10.048 de novembro de 2000. Dá prioridade de atendimento às pessoas que especifica, e dá outras providências. Diário Oficial União. http://www.planalto.gov.br/ccivil_03/leis/110048.htm.

Brasil. Presidência da República, Subchefia para Assuntos Jurídicos. (2000). Lei $n^{\circ} 10.098$ de dezembro de 2000. Estabelece normas gerais e critérios básicos para a promoção da acessibilidade das pessoas portadoras de deficiência ou com mobilidade reduzida, e dá outras providências. Diário Oficial União. http://www.planalto.gov.br/ccivil_03/leis/110098.htm.

Brasil. (2014). Ministério da Saúde. Secretaria de Atenção à Saúde. Departamento de Ações Programáticas Estratégicas. Diretrizes de Atenção à Reabilitação da Pessoa com Transtornos do Espectro do Autismo (TEA). https://bvsms.saude.gov.br/bvs/publicacoes/diretrizes_atencao_reabilitacao_pessoa_autismo.pdf.

Brasil. Ministério da Saúde. (2004). Portaria $n^{o}$. 2.073 de 28 de setembro de 2004.Institue a Política Nacional de Atenção à Saúde Auditiva. http://bvsms.saude.gov.br/bvs/saudelegis/gm/2004/prt2073_28_09_2004.html.

Brasil. Presidência da República, Subchefia para Assuntos Jurídicos. (1996). Lei $n^{\circ} 9.394$ de 20 de dezembro de 1996. Estabelece as diretrizes e bases da educação nacional. Diário Oficial União. http://www.planalto.gov.br/ccivil_03/leis/19394.htm.

Brasil. Presidência da República, subchefia para Assuntos Jurídicos. Lei n 7.853 de 24 de outubro de 1989. (1989). Dispõe sobre o apoio às pessoas portadoras de deficiência, sua integração social, sobre a Coordenadoria Nacional para Integração da Pessoa Portadora de Deficiência - Corde, institui a tutela jurisdicional de interesses coletivos ou difusos dessas pessoas, disciplina a atuação do Ministério Público, define crimes, e dá outras providências. Diário Oficial [da] República Federativa do Brasil. Brasília, DF. 1989 http://www.planalto.gov.br/ccivil_03/leis/17853.htm.

Brasil. Presidência da República, Subchefia para Assuntos Jurídicos. Lei Federal no 12.764 de 27 de dezembro de 2012. (2012). Institui a Política Nacional de Proteção dos Direitos da Pessoa com Transtorno do Espectro Autista; e altera o § 3o do art. 98 da Lei nº 8.112 de 11 de dezembro de 1990 . Diário Oficial [da] República Federativa do Brasil. Brasília, DF. 2012, http://www.planalto.gov.br/ccivil_03/_ato2011-2014/2012/lei/112764.htm.

Câmara, F. S., et al. (2016). Perfil do cuidador de pessoas com deficiência. Rev. bras. ciênc. saúde, 20(4), 269-276.

Filha, F. S. S. C., da Silva, S. R., \& Lando, G. A. (2015). Cuidado ao surdo: conexões com o Direito à Saúde. ReOn Facema 1(1): $31-38$.

França, I. S. X. et al. (2010). Aplicação da bioética principialista às políticas públicas para pessoas com deficiência: revisão sistemática. Online Brazilian Journal of Nursing. http://www.objnursing.uff.br/index.php/nursing/article/view/j.1676-4285.2010.2893/653.

Ganong, L. H. (1987). Integrative reviews of nursing research. Res NursHealth, fev, 10(1), 1-11.

Holanda, E. R., Collet, N., Costa, S. F. G. (2008). Crianças com Síndrome de Down: o significado do cuidar na percepção de mães. Online Brazilian Journal of Nursing, 7 (2), 10. http://www.objnursing.uff.br/index.php/nursing/article/view/j.1676-4285.2008.1443/347.

Instituto Brasileiro de Geografia e Estatística (IBGE). (2012). Censo Demográfico 2010. Características gerais da população, religião e pessoas com deficiência. IBGE.

Kanikadan, P.Y.S., et al. (2019). Custos adicionais da pessoa com deficiência física. Bras Econ Saúde, 11(1), 26-33.

Lima, S. R., \& Mendes, E. G. (2011). Escolarização da pessoa com deficiência intelectual: Terminalidades específicas e expectativas familiares. Revista Brasileira de Educação Especial, 17 (2), 195-208.

Luna, M. B. C. dos S. D., \& Naiff, L. A. M. (2015). Representações sociais da deficiência nas famílias: um estudo comparativo. Psicologia e Saber Social, 4 (1), 19-33.

Maciel, F. J., et al. (2013). Indicadores de saúde auditiva em Minas Gerais: um estudo por macrorregião. Audiol Commun. Res. 18 (4), 275-284: http://dx.doi.org/10.1590/S2317-64312013000400008.

Martins, K. P. et al. (2016). Estrutura interna de Unidades de Saúde da Família: acesso para as pessoas com deficiência. Ciências \& Saúde Coletiva, 21 (10), 3153-3160.

Martins, K., Medeiros, T., Costa, T., Macêdo Costa, K., \& França, I. (2018). Furniture and sanitary facilities in family health units: accessibility for physical disability / Mobiliários e instalações sanitárias em unidades de saúde da família: acessibilidade física para pessoas com deficiência. 2, 10 (4), $1150-1155$. doi:http://dx.doi.org/10.9789/2175-5361.2018.v10i4.1150-1155

Mendes, K. D. S., Silveira, R. C. C. P., \& Galvão, C. M. (2008). Revisão integrativa: método de pesquisa para a incorporação de evidências na saúde e na enfermagem. Texto Contexto Enfermagem, 17(4), 58-64. http://dx.doi.org/10.1590/S0104-07072008000400018

Minatel, M. M., \& Matsukura, T. S. (2014). Famílias de crianças e adolescentes com autismo: Cotidiano e realidade de cuidados em diferentes etapas do desenvolvimento. Rev de Terapia Educacional da Universidade de São Paulo, 25(2), 126- 134.

Minayo, M. C. S. (2006). Desafio do conhecimento: pesquisa qualitativa em saúde. Editora Hucitec.

Ministério da Saúde (BR). Secretaria de Atenção à Saúde. Departamento de Ações Programáticas Estratégicas. (2015). Linha de Cuidado para a Atenção às Pessoas com Transtornos do Espectro do Autismo e suas Famílias na Rede de Atenção Psicossocial do Sistema Único de Saúde. Ministério da Saúde, 2015.

Moher, D., Liberati, A., Tetzlaff, J., \& Altman, D. G. (2009). Preferred reporting items for systematic reviews and meta-analyses: the PRISMA statement. 6 (7), http://journals.plos.org/plosmedicine/article?id=10.1371/journal.pmed.1000097. 
Research, Society and Development, v. 10, n. 5, e36310515029, 2021

(CC BY 4.0) | ISSN 2525-3409 | DOI: http://dx.doi.org/10.33448/rsd-v10i5.15029

Organização Mundial da Saúde (OMS). (2011). Relatório Mundial sobre a Deficiência (World Report on Disability). Tradução: Secretária dos Direitos da Pessoa com Deficiência do Governo do Estado de São Paulo. http://www.pessoacomdeficiencia.sp.gov.br/usr /share/documents/RELATORIO_MUNDIAL_COMPLETO.pdf.

Postalli, L. M. M., Munuera, R. F., Aiello, A. L. R. (2011). Caracterização de Famílias de Mãe com Deficiência Intelectual e os Efeitos no Desenvolvimento dos Filhos. Res. bras. educ. espec., 17 (1). http://dx.doi.org/10.1590/S1413-65382011000100004.

Scarpitta, T. P. P., Vieira, S. S., \& Dupas, G. (2011). Identificando necessidades de crianças com deficiência auditiva: uma contribuição para profissionais de saúde e educação. Esc. Anna Nery (impr.), 15 (4), 791-801.

Silva, S. À., Lohmann, P. M., Costa, A. E. K., \& Marchese, C. (2019). Conhecimento da equipe interprofissional acerca do autismo infantil. Revista Research, Society and Development, 8(9), e07891250. http://dx.doi.org/10.33448/rsd-v8i9.1250

Silveira, A., \& Neves, E. T. (2012). Vulnerabilidade das crianças com necessidades especiais de saúde: implicações para a enfermagem. Revista Gaúcha de Enfermagem, 33(4), 172-180. https://dx.doi.org/10.1590/S1983-14472012000400022

Tavares, T. S., Duarte, E. D., \& Sena, R. R de. (2017). Direitos sociais das crianças com condições crônicas: análise crítica das políticas públicas brasileiras. Escola Anna Nery, 21(4), e20160382. https://dx.doi.org/10.1590/2177-9465-ean-2016-0382

Ursi, E. S., \& Gavão, C. M. (2006). Prevenção de lesões de pele no perioperatório: revisão integrativa da literatura. Rev Latino-am Enfermagem, 14 (1), 124-31, https://www.scielo.br/pdf/rlae/v14n1/v14n1a17.pdf. 